\title{
Online System for Automatic Tropical Wood Recognition
}

\author{
Nenny Ruthfalydia Rosli*, Uswah Khairuddin², Rubiyah Yusof ${ }^{2}$, Hafizza Abdul Ghapar ${ }^{2}$, Anis Salwa \\ Mohd Khairuddin ${ }^{3}$, Nor Azlin Ahmad ${ }^{4}$
}

\author{
${ }^{1}$ Center for Artificial Intelligence \& Robotics (CAIRO), Universiti Teknologi Malaysia, Malaysia. \\ ${ }^{2}$ Malaysia-Japan International Institute of Technology (MJIIT), Universiti Teknologi Malaysia, Malaysia. \\ ${ }^{3}$ Department of Electrical Engineering, Universiti Malaya, Malaysia \\ ${ }^{4}$ Advanced Analytics Engineering Center (AAEC), Faculty of Computer and Mathematical Sciences Universiti Teknologi \\ Mara, Malaysia
}

*Corresponding author: nenny.kl@utm.my, Tel: 603-26154816, Fax: 603-26970815

\begin{abstract}
There are more than 3000 wood species in tropical rainforests, each with their own unique wood anatomy that can be observed using naked eyes aided with a hand glass magnifier for species identification process. However, the number of certified personnel that have this acquired skills are limited due to lenghty training time. To overcome this problem, Center for Artificial Intelligence \& Robotics (CAIRO) has developed an automatic wood recognition system known as KenalKayu that can recognize tropical wood species in less than a second, eliminating laborious manual human inspection which is exposed to human error and biasedness. KenalKayu integrates image acquisition, feature extraction, classifier and machine vision hardware such as camera, interfaces, PC and lighting. Grey level co-occurrence matrix (GLCM) is used for feature extraction. The features are trained in a back-propagation neural network (BPNN) for classification. This paper focusses more on the database development and the online testing of the wood recognition system. The accuracy of the online system is tested on different image quality such as image taken in low light condition, medium light condition or high light condition.
\end{abstract}

Keywords: wood species recognition, pattern recognition, texture analysis.

(C) 2019 Penerbit UTM Press. All rights reserved

Article History: received 4 September 2019; accepted 1 December 2019; published 24 December 2019.

\section{INTRODUCTION}

Malaysia has exported more than RM 23 billions of major timber products such as logs, sawn timber, plywood, veneer, chipboard, fibreboard, wooden frame, builder joinery, wood furniture and also rattan furniture as in December 2017 [1]. This makes Malaysia as one of the world's top tropical timber exporters. There are various ways and efforts that have been taken to empower timber industry in Malaysia. One of them is by enhancing export controls abroad to monitor only authorized timber can be exported while ensuring that the timber is properly labelled and distributed by recognising the wood species. This is to prevent and to detect illegal logging activities that will incur loss to the country.

Currently, manual wood identification based on the anatomy of the wood was carried out by only very few certified personnel in this country [2]. The process of training an expert to perform this job is not easy, due to the fact that there are more than 3,000 species of wood in the Malaysian jungle [3]. Thus, there is an urgent need to apply a more structured way in performing wood identification such that wood identification can be carried out fairly accurately and quickly. Centre for Artificial Intelligence and Robotics (CAIRO) has developed an automatic wood recognition system known as KenalKayu to overcome this problem [4]-[10].
The system recognizes wood species based on wood macroscopic features as shown in Figure 1. The research has started since 2002 and it has been improved in many phases [10]-[20] to ensure the system's ability to recognise wood species in both offline or online mode. This system may replace the conventional technique in performing wood identification which is exposed to human error and biasedness.

Kenalkayu can recognise a wood species in less than a second. This may save time, cost and human resources in performing wood identification. It is also organised and systematic with Wood Database Management System developed within the system. Moreover, KenalKayu is a web-based system and can be accessed anywhere as long it is connected to the internet.

For demo purposes, a PC-based Kenalkayu system are used for experimental data collection and analysis as well as for training and testing [21]. A microscopic camera has been attached to the system and was equipped with a lighting system. The demo system only contains 10 wood timber group database.

The accuracy for the offline testing is up to $97 \%$. However, for online testing using new wood cubes, the accuracy is decreasing. In this paper, the online system's performance was observed when capturing images in different image quality setting, which are different level of brightness and image clarity. The next chapter will explain 
the methodology and testing setup before continuing to results and discussion section and ends with a conclusion.

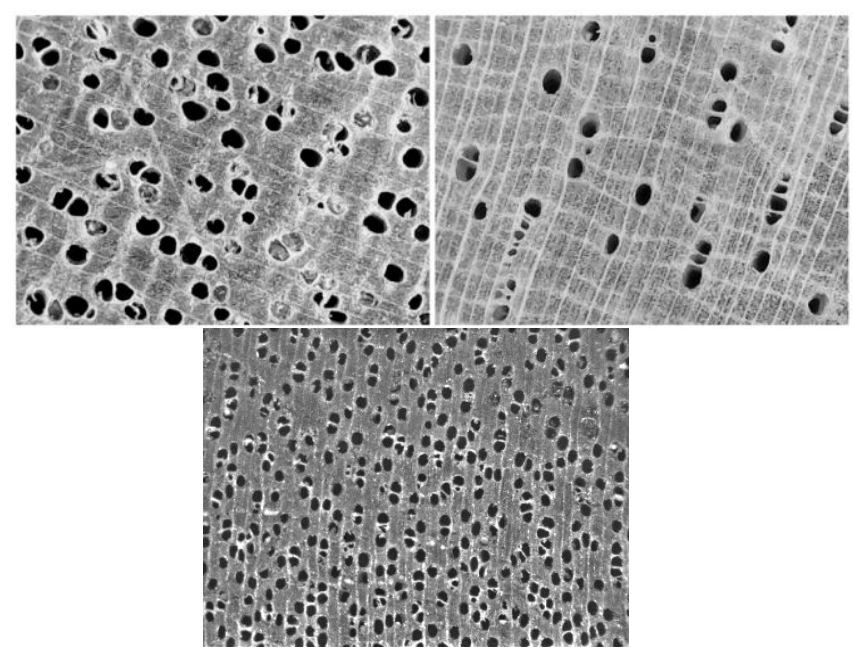

Figure 1. Example of Wood Anatomy

\section{METHODOLOGY}

This section explains the approaches that have been used for this research. Figure 2 shows the general flow chart for KenalKayu online testing system. The system can identify tropical wood species very well and the accuracy rate for the system is up to $97 \%$ [15] in offline mode. The input for the system is a raw wood anatomy image captured by a microscopic camera. Then the texture will be analysed and it's features will be extracted using grey level cooccurrence matrix (GLCM) technique. The features were trained in a back-propagation neural network (BPNN), one of the artificial neural network method. As a result, the wood species will be given as the output for the system.

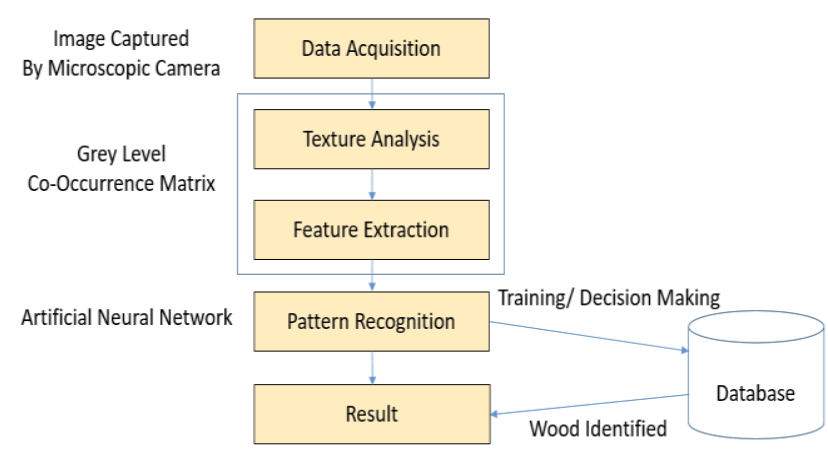

Figure 2. Process flow for KenalKayu

In GLCM technique, textural features of an image are based on the theory that the texture information on an image is contained in the overall or average spatial relationship which the grey tones in the image have with one another. More precisely, this texture information is adequately specified by a set of grey tone spatial dependence matrices; that are computed for various angular relationships and distances between neighboring resolution cell pairs on the image. The features from these grey tone spatial dependence matrices.

For each input image, the co-occurrence matrices are calculated from four directions, which are horizontal, vertical, diagonal $45^{\circ}$ and diagonal $135^{\circ}$. A new matrix is formed as the average of these matrices that are used for extracting the features. In this manner, the extracted features will be rotation invariant at least for $45^{\circ}$ steps of rotation. For each orientation of an image, there are 5 features to be extracted which are the angular second moment, contrast, correlation, entropy and inverse difference moment. This will give the total of 20 features to be extracted using this feature extractor. Table 1 shows the features extracted using GLCM.

Table 1. Features extracted using GLCM

\begin{tabular}{|l|l|}
\hline $\begin{array}{l}\text { Angular } \\
\text { Mocond }\end{array}$ & $f_{1}=\sum_{i} \sum_{j}\{P(i, j)\}^{2}$ \\
\hline Contrast & $f_{2}=\sum_{n=0}^{N-1} n^{2}\left\{\sum_{i=1}^{N} \sum_{j=1}^{N} P(i, j)\right\}$ \\
\hline Correlation & $\sum_{i} \sum_{j}(i j) P_{i j}-\mu_{x} \mu_{y}$ \\
\hline Entropy & $f_{x} \sigma_{x} \sigma_{y}$ \\
\hline $\begin{array}{l}\text { Inverse } \\
\text { Difference } \\
\text { Moment }\end{array}$ & $f_{4}=-\sum_{i} \sum_{j}$ and $\mu_{i j}$ are mean $\log \left(P_{i j}\right)$ \\
\hline
\end{tabular}

BPNN was used as the classification technique. It consists of a series of input neurons, a hidden layer and a layer of output neurons. These layers are fully connected. Each input neuron represents the textural features and the output neuron represents a distinct image type. Input parameters are normalized and scaled to a range of 0 to 1 and the output values for each mineral are presented as probabilities in the range of 0 to 1 . The nature of each function and each weight within the network is determined during the training process. By propagating corrections based on the squared error back through the network, the next cycle will modify the weight matrices and bias values until the network converges to a correct solution.

Wood samples for this paper are obtained from the Forest Research Institute of Malaysia (FRIM) in cubic form with size of 1 inch by 1 inch each. There are 5 to 20 wood cubes provided for each species. These different cubes may come from the same tree or different trees depending on stock availability in FRIM's wood library. Figure 3 shows the wood sample with three different wood surfaces.

The wood anatomy image has been captured by using a microscopic camera which is MAXGear Digital Microscope HD USB Camera as shown in Figure 4. The camera equipped with built in 8 pieces of white light LED and manual brightness controller. In this paper, 10 different types of tropical woods species which are Bintangor, Chengal, Durian, Gerutu, Jelutong, Sesendok, Ramin, Perupok, Melunak and Keranji were tested. There were a total of 152 cubes used in this experiment. 


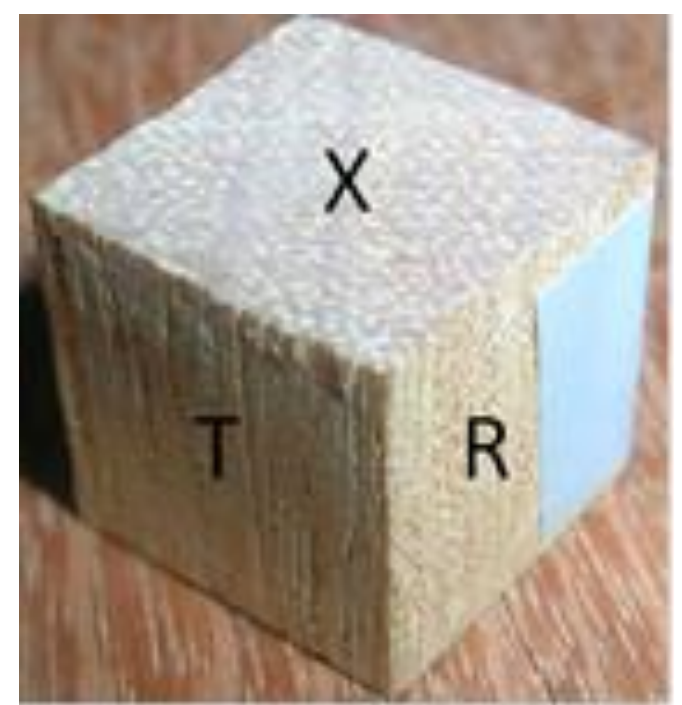

Figure 3. The three wood surfaces; $(\mathrm{X})$ cross section surface, $(\mathrm{T})$ tangential surface and $(\mathrm{R})$ radial surface.

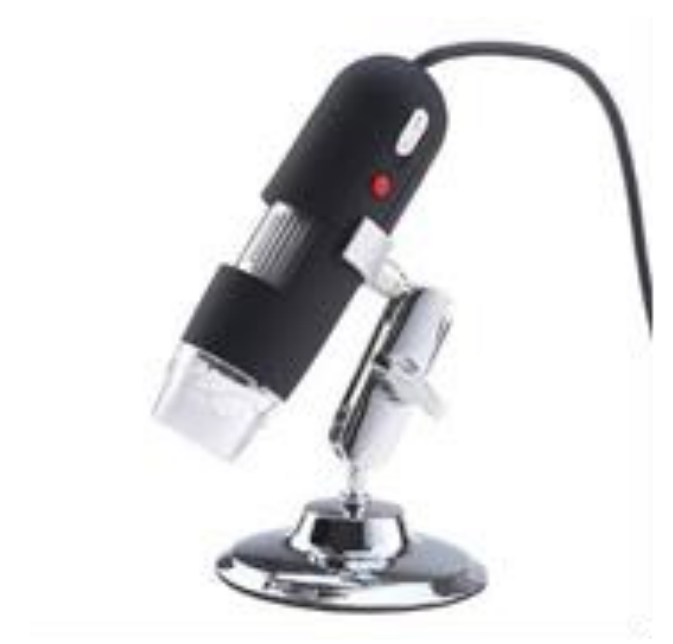

Figure 4. MAXGear Digital Microscope HD USB Camera

In order to test the performance of the online system, each wood surface images were captured forty times using the camera where the first thirty images were taken under different lighting conditions; $100 \%$ brightness (10 images), $50 \%$ brightness (10 images) and no light at all (10 images). The final 10 images capturing was carried out in a specific way that produces blurry images. This procedure was repeated for each wood cube in the database. Overall, a total of 1520 images were taken from these wood cube samples.

The online system output is not a single species statement; however, it listed all wood timber group in the database (10 groups in this system) and give the percentage of similarity between the test wood sample to each of the timber group. In this case, if the similarity percentage is more than $60 \%$, it will be accepted as the match for the test wood sample.

There are two ways of grouping the wood species; by grouping them according to their subspecies or their timber group. In this study, all species are classified by their timber group's name. Table 2 shows the number of wood cube samples according to timber group.

Table 2. Number of wood samples

\begin{tabular}{|c|l|c|}
\hline No & $\begin{array}{l}\text { Timber } \\
\text { Group }\end{array}$ & No. of Wood cube Sample \\
\hline 1 & Bintangor & 17 \\
\hline 2 & Chengal & 13 \\
\hline 3 & Durian & 15 \\
\hline 4 & Gerutu & 18 \\
\hline 5 & Jelutong & 12 \\
\hline 6 & Sesendok & 10 \\
\hline 7 & Ramin & 16 \\
\hline 8 & Perupok & 18 \\
\hline 9 & Melunak & 16 \\
\hline 10 & Keranji & 17 \\
\hline & Grand Total: & $\underline{\mathbf{1 5 2}}$ \\
\hline
\end{tabular}

\section{RESULTS \& DISCUSSION}

The online testing was carried out on the 10 wood timber group samples and the success rate were determined according to the classification performance of individual wood cubes in each timber group. Table 3 shows the overall result for the online testing. The values in the table are number of wood cubes correctly classified. The overall success rate of $52 \%$ (for $100 \%$ brightness) is quite low compared to the previous offline testing (97\%), however, this might be caused by low number of samples included in the training set and most of wood cubes used for online testing are new and not included in the training set.

Timber groups that have more than $80 \%$ success rate are Chengal (84.6\% at $50 \%$ brightness) Durian $(86.6 \%$ at $100 \%$ brightness) and Perupok (94.4\% for blur images). Interestingly for Chengal timber group, when the lighting was full at $100 \%$, the success rate dropped to $69.2 \%$. Looking at the sample images from the same wood cube for Chengal timber group taken at $100 \%$ and $50 \%$ brightness (Figure 5), when the brightness level was at $100 \%$, the light exposure caused reduction in image contrast. As a result, parenchyma rays are slightly more difficult to be extracted compared to the image in $50 \%$ brightness level. Parenchyma rays are important discriminating features in tropical wood species and when this feature was not extracted fully, classification accuracy will be reduced.

Perhaps the most interesting observation is for Perupok timber group where high success rate $(72.2 \%)$ are obtained when brightness level is at $0 \%$ and the highest success rate was for blur images (94.4\%). Figure 6 shows images of the same wood cube from Perupok timber group in different image quality. The top two images $(100 \%$ and $50 \%$ brightness) were misclassified as Bintangor, while the bottom two images ( $0 \%$ brightness and blur image) was correctly classified as Perupok. This timber group has dense parenchyma rays and vertical canals. When the images are clear and under good lighting, both parenchyma rays and canals are visible and will be easily misclassified as timber group Bintangor which have dense parenchyma rays as well. However, when there is no lighting or when the image is blur, the parenchyma rays were less visible, while increasing the contrast of the vertical canals, which may be important discriminative features for Perupok. 
Table 3. Success rate for each timber group in online testing (more than $60 \%$ similarity percentage based on each wood cube)

\begin{tabular}{|c|c|c|c|c|c|}
\hline \multirow[b]{2}{*}{$\begin{array}{l}\text { Timber } \\
\text { Group }\end{array}$} & \multirow[b]{2}{*}{$\begin{array}{l}\text { No of } \\
\text { Wood } \\
\text { Cubes }\end{array}$} & \multicolumn{4}{|c|}{ Success Rate } \\
\hline & & $\begin{array}{c}\text { Clear } \\
\text { Images } \\
(100 \% \\
\text { Bright })\end{array}$ & $\begin{array}{c}\text { Clear } \\
\text { Images } \\
(50 \% \\
\text { Bright })\end{array}$ & $\begin{array}{c}\text { Clear } \\
\text { Images } \\
(0 \% \\
\text { Bright })\end{array}$ & $\begin{array}{c}\text { Blur } \\
\text { Images }\end{array}$ \\
\hline Bintangor & 17 & $\begin{array}{c}11 \\
(64.7 \%)\end{array}$ & $\begin{array}{c}8 \\
(47 \%)\end{array}$ & $\begin{array}{c}10 \\
(58.8 \%)\end{array}$ & $\begin{array}{c}5 \\
(29.4 \%)\end{array}$ \\
\hline Chengal & 13 & $\begin{array}{c}9 \\
(69.2 \%)\end{array}$ & $\begin{array}{c}11 \\
(84.6 \%)\end{array}$ & $\begin{array}{c}9 \\
(69.2 \%)\end{array}$ & $\begin{array}{c}1 \\
(7.7 \%)\end{array}$ \\
\hline Durian & 15 & $\begin{array}{c}13 \\
(86.6 \%)\end{array}$ & $\begin{array}{c}6 \\
(40.0 \%)\end{array}$ & $\begin{array}{c}2 \\
(13.3 \%)\end{array}$ & $\begin{array}{c}0 \\
(0.0 \%)\end{array}$ \\
\hline Gerutu & 18 & $\begin{array}{c}3 \\
(16.6 \%)\end{array}$ & $\begin{array}{c}5 \\
(27.7 \%)\end{array}$ & $\begin{array}{c}7 \\
(38.8 \%)\end{array}$ & $\begin{array}{c}2 \\
(11.1 \%)\end{array}$ \\
\hline Jelutong & 12 & $\begin{array}{c}7 \\
(58.3 \%) \\
\end{array}$ & $\begin{array}{c}4 \\
(33.3 \%) \\
\end{array}$ & $\begin{array}{c}2 \\
(16.6 \%)\end{array}$ & $\begin{array}{c}0 \\
(0.0 \%)\end{array}$ \\
\hline Sesendok & 10 & $\begin{array}{c}5 \\
(50.0 \%)\end{array}$ & $\begin{array}{c}4 \\
(40.0 \%)\end{array}$ & $\begin{array}{c}3 \\
(30.0 \%)\end{array}$ & $\begin{array}{c}0 \\
(0.0 \%)\end{array}$ \\
\hline Ramin & 16 & $\begin{array}{c}7 \\
(43.7 \%)\end{array}$ & $\begin{array}{c}7 \\
(43.7 \%)\end{array}$ & $\begin{array}{c}5 \\
(31.2 \%)\end{array}$ & $\begin{array}{c}0 \\
(0.0 \%)\end{array}$ \\
\hline Perupok & 18 & $\begin{array}{c}11 \\
(61.1 \%)\end{array}$ & $\begin{array}{c}9 \\
(50.0 \%)\end{array}$ & $\begin{array}{c}13 \\
(72.2 \%)\end{array}$ & $\begin{array}{c}17 \\
(94.4 \%)\end{array}$ \\
\hline Melunak & 16 & $\begin{array}{c}10 \\
(62.5 \%)\end{array}$ & $\begin{array}{c}7 \\
(43.7 \%)\end{array}$ & $\begin{array}{c}3 \\
(18.7 \%)\end{array}$ & $\begin{array}{c}0 \\
(0.0 \%)\end{array}$ \\
\hline Keranji & 17 & $\begin{array}{c}1 \\
(5.8 \%)\end{array}$ & $\begin{array}{c}0 \\
(0.0 \%)\end{array}$ & $\begin{array}{c}0 \\
(0.0 \%)\end{array}$ & $\begin{array}{c}0 \\
(0.0 \%)\end{array}$ \\
\hline \multicolumn{2}{|c|}{ Total } & $51.85 \%$ & $41.0 \%$ & $34.8 \%$ & $14.2 \%$ \\
\hline
\end{tabular}

The high success rate on blur images of Perupok is unique to this timber group only. However, it shows that removing features that are not discriminative will increase the chance of the wood to be correctly classified.

Perhaps the most interesting observation is for Perupok timber group where high success rate $(72.2 \%)$ are obtained when brightness level is at $0 \%$ and the highest success rate was for blur images (94.4\%). Figure 6 shows images of the same wood cube from Perupok timber group in different image quality. The top two images $(100 \%$ and $50 \%$ brightness) were misclassified as Bintangor, while the bottom two images ( $0 \%$ brightness and blur image) was correctly classified as Perupok. This timber group has dense parenchyma rays and vertical canals. When the images are clear and under good lighting, both parenchyma rays and canals are visible and will be easily misclassified as timber group Bintangor which have dense parenchyma rays as well. However, when there is no lighting or when the image is blur, the parenchyma rays were less visible, while increasing the contrast of the vertical canals, which may be important discriminative features for Perupok.

The high success rate on blur images of Perupok is unique to this timber group only. However, it shows that removing features that are not discriminative will increase the chance of the wood to be correctly classified.

From Table 3, Overall success rate is the highest when the brightness level is at $100 \%$, followed by $50 \%$ brightness level, no lighting and blur image. It shows that image quality is very important when carrying out image recognition exercises.

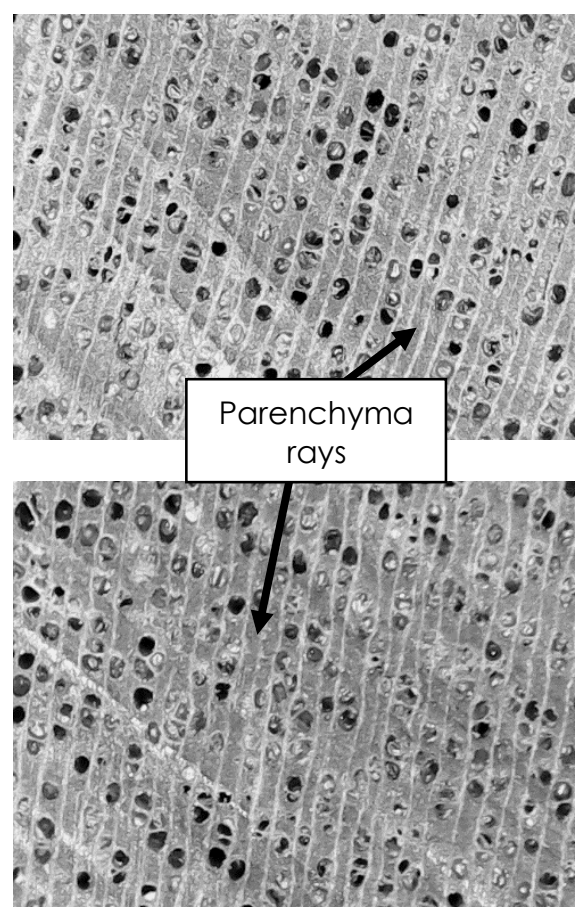

Figure 5. Chengal at $100 \%$ brightness (top) and $50 \%$ brightness (bottom)

\section{CONCLUSSION}

The study was to observe the performance of an online wood recognition system when using different image quality. The quality of image was differentiated by setting the brightness level of an inset camera to $100 \%, 50 \%$, and $0 \%$, and additional blur image (camera not focus). While it is expected to have highest classification success rate when using $100 \%$ brightness level, as shown in the results section, there are some unique cases where the timber group are more recognizable when the image quality is lower, for example for timber group Perupok. In the case of Chengal, its darker background actually helps highlighting parenchyma rays. When $100 \%$ light was used, the contrast are reduced, hence lowering the chance for the wood to be correctly classified.

Compared to offline testing results, the overall success rate of this online testing system is only $51.85 \%$. It is best to increase training samples in future work in order to increase the performance of the online system or divide each wood cube according to its sub-species, not a big timber group. The finding from this study on different image quality might be useful for future work in determining which features are the most discriminative for each wood species.

\section{ACKNOWLEDGMENT}

The authors would like to thank Malaysia-Japan Institute of Technology (MJIIT), Universiti Teknologi Malaysia for funding this research through a research grant entitled "Enhancement of Tropical Wood Species Accuracy" (vote number 4J006). 

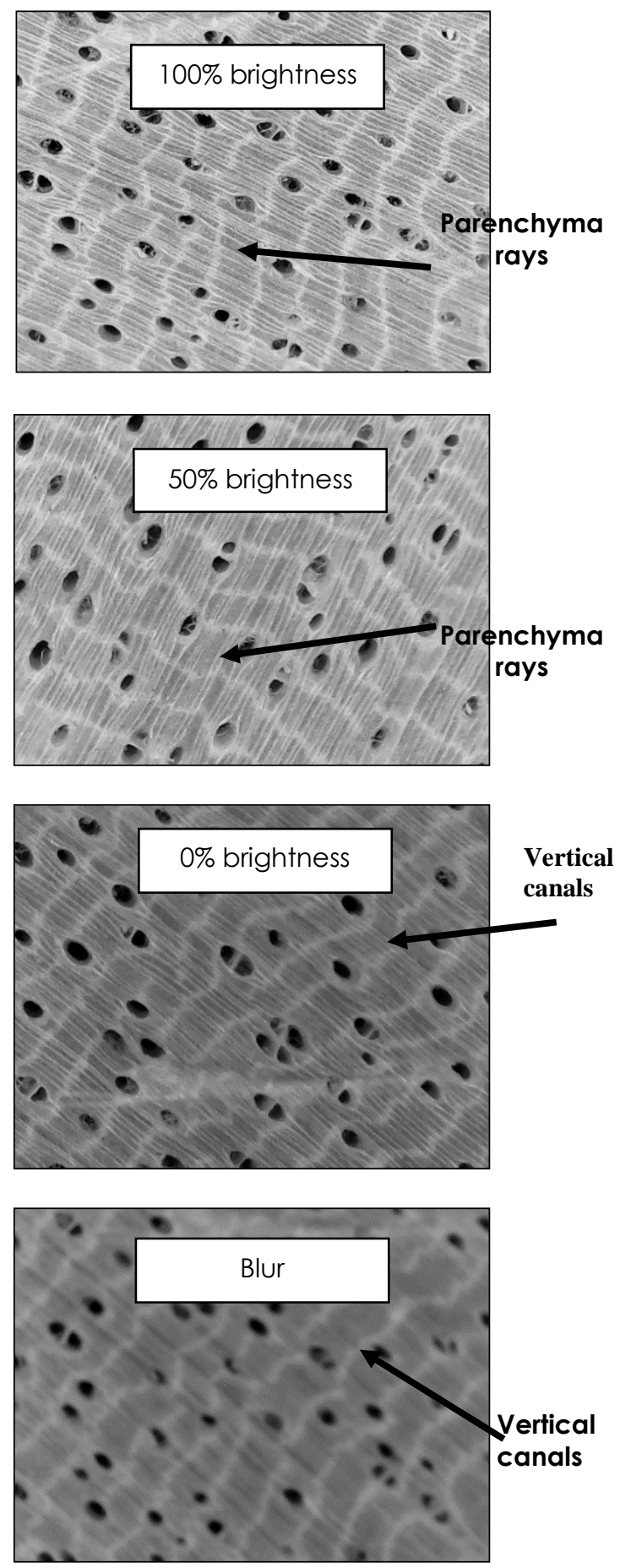

Figure 6. Perupok timber group at different image quality

\section{REFERENCES}

[1] Ooi Tee Ching, "Malaysia's 2017 timber exports to surpass RM23b", "New Straits Times", Business, January 21 st, 2018

[2] U.Khairuddin, R.Yusof, N.R.Rosli, "A Comparative Study of k-NN and MLP-NN Classifiers Using GAkNN Based Feature Selection Method for Wood Recognition System", 17th International Conference on Electrical, Control and Automation Engineering (ICECAE 2015), WASET, Vol.2 (4), pp.26952699,eISSN:1307-6892, 8-9 March 2015.

[3] M.Khalid, E.L.Y.Lee, R.Yusof, M.Nadaraj, "Design of an Intelligent Wood Species Recognition",
International Journal of Simulation System, Science and Technology, IJSSST, Vol. 9 (3), pp. 9-19, ISSN: 1473-8031, September 2008.

[4] F A. Wheeler and P. Baas, "Wood Identification - A review”. IAWA Journal, 19(3):pp. 241-264, 1998

[5] Fuentealba, C., Simon, C. et al. "Wood products identification by internal characteristics readings". Proceedings of the IEEE International Conference on Industrial Technology, Hammamet 2004

[6] Baas, P., E. Wheeler, et al. (2000). "Dicotyledonous wood anatomy and the APG system of angiosperm classification." Botanical Journal of the Linnean Society 134(1-2): 3-17.

[7] Jing Yi Tao, Phooi Yee Lau and Yong Haur Tay, Computer Vision-based Wood Recognition System, International Workshop on Advanced Image Technology (IWAIT), Jan 2007, Bangkok., January 2007.

[8] Jing Yi Tou, Yong Haur Tay, Phooi Yee Lau, A Comparative Study for Texture Classification Techniques on Wood Species Recognition Problem, fifth International Conference on Natural Computation (ICNC 2009), August 2009.

[9] Jing Yi Tou, Yong Haur Tay, \& Phooi Yee Lau, Rotational Invariant Wood Species Recognition through Wood Species Verification, In N. T. Nguyen, H. P. Nguyen, \& A. Grzech (Ed.), Proceedings 1st Asian Conference on Intelligent Information and Database Systems (ACIIDS 2009) (pp. 115-120). Dong Hoi, April 2009.

[10] Tou, J. Y., Tay, Y. H., \& Lau, P. Y, A Comparative Study for Texture Classification Techniques on Wood Species Recognition Problem, Proceedings fifth International Conference on Natural Computation (ICNC 2009), August 2009.

[11] N.R. Rosli, M. Khalid, R. Yusof, 'Wood Species Recognition based on Gabor Filter Image Processing Technique", 2008 Student Conference on Research and Development (SCORED 2008), pp.194-1-194-4, 26-27 Nov 2008.

[12] R. Yusof, N.R. Rosli, M. Khalid, "Tropical Wood Species Recognition Based on Gabor Filter", 2nd International Congress on Image and Signal Processing, Vols 1-9, IEEE, pp. 2705-2709, ISBN: 978-1-4244-4129-7, 17-19 Oct 2009.

[13] R. Yusof, N.R. Rosli, M. Khalid, "Using Gabor Filters as Image Multiplier for Tropical Wood Species Recognition System",12th International Conference on Computer Modelling and Simulation (UKSIM), IEEE, pp. 289-294, Article no. 5481196, ISBN: 9780-7695-4016-0, 24-26 March 2010.

[14] R. Yusof, N.R. Rosli, "Tropical Wood Species Recognition System Based on Gabor Filter as Image Multiplier", Proceeding 2013 International Conference on Signal-Image Technology and Internet-Based Systems (SITIS 2013), IEEE, Vol. 2013, pp. 737-743, ISBN: 978-147993211-5, 2-5 December 2013.

[15] W.A.H.W.A. Halim, R. Yusof, N.R. Rosli, "Integration of Conveyor System with Tropical Wood Species Recognition System", National Conference on Wood Based Technology, Engineering and Innovation 2015 (NCWEI'15), $17-$ 18 November 2015. 
[16] R. Yusof, N.R. Rosli, F.N.A. Bakar, "Non-Wood Anatomy Image Detector for Tropical Wood Recognition System", 4th Kuala Lumpur International Agriculture, Forestry \& Plantation Conference 2016 (KLIAP 2016), pp162-168, ISBN: 978-967-2072-01-0, 12-13 December 2016.

[17] R.Yusof, A.Ahmad. M.N. Ismail, N.R. Rosli, "Clustering the Imbalance Data Sets Using Modified Kohonen Self-Organizing Map (KSOM)", IEEE Technically Sponsores Computing Conference 2017, 18th-20th July 2017.

[18] A.Ahmad, R.Yusof, "Refining the Scatteredness of Classes using Pheromone-Based Kohonen SelfOrganizing Map (PKSOM)", INTELLI 2014 : The Third International Conference on Intelligent Systems and Applications, IARIA, pp. 107-113, ISSN: 2308-4065, 22-26 June 2014.

[19] A.Ahmad, R.Yusof, "Determining the Dominant Tropical Wood Species in KSOM Clustering using Histogram Intersection (HI)", the 2nd Mini Symposium on Artificial Intelligence and Robotics (AIR2014), CAIRO, August 2014.

[20] R.Yusof, M.Khalid, A.S.M.Khairuddin, "Fuzzy Data Management On Pores Arrangement for Tropical Wood Species Recognition System", Proceedings of 2013 Science and Information Conference (SAI
2013), IEEE, pp. 529-535, ISBN: 978-098931930-0, 7-9 October 2013.

[21] A.Ahmad, R.Yusof, "Clustering the Tropical Wood Species Using Kohonen Self-Organizing Map (KSOM)",Proceedings Of The 2nd International Conference on Advances in Computer Science and Engineering (CSE 2013), Atlantis Press, Vol. 42,pp. 16-19, ISSN: 1951-6851, 1-2 July 2013.

[22] U.Khairuddin, R.Yusof, M.Khalid, F.Cordova, "Optimized Feature Selection for Improved Tropical Wood Species Recognition System", ICIC Express Letters, Part B: Applications, ICIC Express Letters, Vol. 2 (2), pp. 441-446, ISSN 2185-2766, April 2011.

[23] R.Yusof, M.Khalid, A.S.M.Khairuddin, "Application of Kernel-Genetic Algorithm as Nonlinear Feature Selection in Tropical Wood Species Recognition System", Computers and Electronics in Agriculture, Elsevier Sci Ltd, Vol. 93, pp. 68-77, ISSN: 0168-1699, April 2013. (ISI Rank: Q1, IF : 1.766)

[24] A.Ahmad, R.Yusof, "A modified kohonen selforganizing map (KSOM) clustering for four categorical data", Jurnal Teknologi, UTM Press, Vol. 78(6-13), pp. 75-80, ISSN: 0127-9696, 2016. 